\title{
A TEORIA DA LIBIDO EM FREUD COMO UMA HIPÓTESE ESPECULATIVA*
}

Leopoldo Fulgencio

Doutor em Psicologia Clínica pelo Programa dos Estudos PósGraduadosem Psicologia Clínica da PUC-SP; psicanalista; membro do Departamento de Psicanálise do Instituto Sedes Sapientiae.
RESUMO: Comenta-se a distinção freudiana entre a sexualidade, como um fato observável, e a libido, como uma hipótese especulativa, mostrando que, para Freud, a suposição de uma energia específica para a pulsão sexual corresponde a um conceito que tem validade apenas instrumental - ou seja, heurística - não sendo uma referência empírica objetiva. Salienta-se que Freud não considera os conceitos desse tipo - especulativos - o fundamento da sua ciência, mas sim o cume substituível do edifício teórico da psicanálise. Esse tipo de interpretação da obra de Freud, que o integra na história da filosofia e da ciência alemãs, permite não só compreender a psicanálise como uma ciência numa perspectiva heurística, como também possibilita uma análise dos desenvolvimentos da psicanálise levando em conta a diferença entre dados empíricos e teóricos (especulativos), e explicando, assim, em que sentido a teoria psicanalítica é considerada por Freud como provisória e sempre aberta a revisões.

Palavras-chave: Sexualidade, libido, especulação, heurística, psicanálise.

ABSTRACT: Freud's theory of libido as a speculative hypothesis. This article comments on the Freudian distinction between sexuality, as an observable fact, and libido, as a speculative hypothesis,

\footnotetext{
* Apresento aqui um dos resultados (não incluído na dissertação) que obtive na pesquisa para a minha tese de doutorado "O método especulativo em Freud", PUC-SP, 2001. A pesquisa e seus resultados se inserem numa linha fundada a partir dos trabalhos de Zeljko Loparic, que tem sido desenvolvida com resultados expressivos pelo Grupo de Pesqui sa em Filosofia e Práticas Psicoterápicas (Grupofpp) no Programa de Estudos Pós-Graduados em Psi cologia Clínica da PU C-SP, tanto no que diz respeito à análise do lugar epistemológico e metodológico da psicanálise, quanto no que se refere a uma revolução nessa disciplina, creditada a Winnicott (enquanto tendo desenvolvido uma psicanálise sem especulações, ou seja, sem a metapsicologia). Confira a lista dos resultados até agora obtidos e das pesquisas em andamento no site www.cle.unicamp.br/grupofpp.
} 
demonstrating that, for Freud, the supposition of a specific energy for sexual drive corresponds to a concept that has only instrumental - or heuristic - validity rather than an objective empirical reference. It is also pointed out that Freud does not consider the concepts of this type - speculative - to be the basis of his science, but the replaceable apogee of the theoretical edifice of psychoanalysis. This type of interpretation of Freud's work, which integrates it in the history of German philosophy and science, permits not only the comprehension of psychoanalysis as a science from a heuristic perspective but also makes possible an analysis of the developments of psychoanalysis that takes into account the difference between empirical and theoretical (speculative) data, explaining in what sense the psychoanalytical theory is considered by Freud as provisional and always open to revisions.

Keywords: Sexuality, libido, speculation, heuristic, psychoanalysis.

\section{A} sexualidade não é a libido. Quando Freud se refere aos fenômenos observáveis relativos à vida sexual (seja no seu sentido estrito, seja no expandido, mais adequado à psicanálise), ele está apoiado em dados passíveis de comprovação empírica. Mas, ao dizer libido, Freud associa esse mesmo conjunto de fatos empíricos a uma suposta energia psíquica: a energia das pulsões sexuais. Pretendo mostrar que, para Freud, a libido não corresponde a um conceito do qual se espera uma referência empírica objetiva, mas sim uma especulação teórica, de valor apenas heurístico, ou seja, útil para explicar determinados fatos psíquicos. ${ }^{1}$

Ao pressupor a existência de forças psíquicas ( pul sões) em conflito - como aquilo a que se deve responsabilizar como sendo a causa psíquica originária (atrás da qual nenhuma outra deve ser considerada) dos fenômenos psíquicos - Freud considerará útil também acrescentar (no caminho de construção da sua psicologia como uma ciência natural) a existência de uma dimensão quantitativa dessas pulsões: "Nós a representamos [a pulsão] como um certo montante de energia que impulsiona numa direção determinada" (FREUD, 1933al lição32, p. 179; SE, XXIII, p. 96).²

\footnotetext{
${ }^{1} \mathrm{Nem}$ sempre a distinção entre o que é empírico e o que é especulativo na doutrina psicanalítica foi feita pelos autores pós-Freud, o que pode não só atrapalhar a compreensão das propostas freudianas como também levar a concepções epistemológicas errôneas sobre a natureza dos concei tos e teorias da ciência psicanalítica.

${ }^{2}$ A referência aos textos de Freud ( por exemplo: FREUD, 1914c) corresponde à Chronological Handlist of Freud'sW orks (International Journal of Psycho- analysis, 1956), feita por Tyson-Strachey. Essa mesma notação é adotada nas versões alemãs das obras completas de Freud - GesammetteW erke (GA), Studienausgabe (SA) - , na tradução em língua espanhola - organizada por Echeverry, editada pela Amorrortu Editores ( $A E)$ - e na tradução francesa aqui utilizada, dirigida por Jean Laplanche (OCF.P). N este artigo, o lei tor encontrará referências aos textos efetivamente utilizados e a cor-
} 
A pulsão é, para ele, uma idéa abstrata, um conceito fundamental convencional necessário à psicologia (FREUD, 1915c, p. 163-164; SE, XIV, p. 117), logo, distinto de um conceito empírico. ${ }^{3}$ Ela corresponde a um conceito metapsicológico, quer dizer, a um conceito que está para além dos dados descritivos, introduzido como necessário à aplicação de um ponto de vista dinâmico, que servirá a Freud como um princípio metodológico a priori: “N ós nos esforçamos para estabelecer uma concepção dinâmica dos fenômenos anímicos. Os fenômenos percebidos devem, segundo nossa concepção, ceder lugar para as tendências que nós apenas supomos" (FREUD, 1916-17, p. 65; SE, XV, p. 67). Para Freud é aí que reside a marca da diferença entre a psicanálise e as outras psicologias: "ela propõe, no lugar de uma simples descrição, uma explicação dinâmica fundada na interação de forças psíquicas" (FREUD, 1913m, p. 29-30; SE, XIII, p. 207).

Na fundação da psicanálise, portanto, está essa tomada de posição a favor da concepção dinâmica, que, por sua vez, exigirá uma dimensão econômica: "eu passei da apresentação descritiva à concepção dinâmica, desta a uma concepção dita 'econômica'" (FREUD, 1916-17, p. 391; SE, XV, p. 378). Assim, há que se considerar uma dependência entre a teoria das pulsões e a teoria das energias psíquicas, este fato fica claro quando Freud indica de onde retirou o termo para usar na sua metapsicologia: "Libido é um termo vindo da doutrina das pulsões, já utilizado nesse sentido por A. Moll (Pesquisas sobre a libido sexualis, 1898) para designar a expressão dinâmica da sexualidade, introduzida na psicanálise pelo autor destas linhas" (FREUD, 1923a, p. 204; SE, XVIII, p. 255). Ou seja, ela corresponde ao aspecto quantitativo que se agrega ao ponto de vista dinâmico ai nda que a libido seja uma energia impossível de ser mensurada (cf. FREUD, 1912c, p. 125; SE, XII, p. 236) - , associando às pulsões um componente que permite explicar as diversas graduações e deslocamentos de seus investimentos: "Foram primeiramente objeto de nosso estudo somente as pulsões sexuais cuja energia nós chamamos de libido" (FREUD, 1933a/ lição32, p. 179; SE, XXII, p. 96).

Quando Freud apresenta certos desenvolvimentos da psicanálise nas suas Novas conferências, ele toma a teoria das pulsões e a teoria da libido como teorias quase sinônimas: "Tenho o projeto de levá-los, a partir de hoje, ao domínio da teoria da libido ou doutrina das pulsões, na qual muitas coisas tomaram igualmente uma nova configuração" (FREUD, 1933a/ lição32, p. 177; SE, XXII, p. 94). Nesse mesmo texto, ele afirma que a teoria das pulsões é sua mitologia, logo, a

respondente paginação destes na Standard Edition inglesa (SE) - feita com o apoio de tabela publicada na $\mathrm{AE}$ - , com a especificação complementar do volume onde se encontra 0 texto referido na SE ( por exemplo: FREUD, 1933a/ lição32, p. 179; SE, XXIII, p. 96).

${ }_{3}^{3}$ Para uma análise do conceito de Trieb na filosofia alemã e na psi canálise, veja, por exemplo, em LOPARIC, 1999. 
teoria da libido também deve ser assim considerada, ou seja, tanto as forças psíquicas (pulsões) quanto as energias psíquicas de caráter sexual (libido) devem ser consideradas como conceitos que são mitos e, portanto, conceitos que não têm um referente empírico determinável.

Não se trata nem mesmo de considerar a libido como uma energia tal como já foi proposta noutros ramos das ciências naturais, seja na física ( dado que ela não corresponde a nenhuma das energias aí nomeadas) seja na biologia (onde são supostas energias bioquímicas). Rapaport já observou essa diferença:

"A energia muscular do comportamento não é a energia psicológica da qual fala a teoria psicanalítica: as forças psicológicas que, em sua atuação utilizam a psicológica, somente libertam as forças que usam a energia bioquímica dos músculos. [...] A energia psicológica é considerada como de origem impulsiva." (RAPAPORT, 1982, p. 60)

Isso não quer dizer que em outras ciências os conceitos de força e de energia estejam melhor situados, como se na psicanálise eles correspondessem a especulações enquanto que, noutras ciências, corresponderiam a fatos empíricos observáveis diretamente (e não apenas por seus efeitos). Para Freud, os conceitos fundamentais da psicanálise são tão obscuros quanto os que estão na base de outras ciências naturais: "Fazemos ainda, em nossos dias, a mesma experiência na física: suas intuições fundamentais sobre a matéria, os centros de força, a atração etc., são tão menos problemáticas que as concepções correspondentes em psicanálise" (FREUD, 1914c, p. 85; SE, XIV, p. 76). Somente a filosofia ou as ciências do espírito partiriam de conceitos claros e distintos, logicamente irrepreensíveis, seguindo, então, para a construção de um edifício teórico completo sem contradições e sem lacunas. Além disso, o cientista (da natureza) está sempre limitado e delimitado por um conjunto de fatos que ele apreende representando-0s, não na sua totalidade, mas segundo certos aspectos considerados relevantes, ou seja, ele reduz os fatos substituindo-os pelos fatos-representados. Será operando sobre essas representações que o cientista tentará explicar os fenômenos e suas relações de determinação recíproca. 0 ponto de partida sela, portanto, uma incompletude: os fatos são sempre mais ricos e mais complexos do que suas representações. Isso leva o cientista a, necessariamente, reconhecer suas teorias como incompletas e cheias de lacunas, as quais ele espera cobrir com o desenvolvimento das suas pesquisas. Freud sabe que é assim que ocorre na física, e defende que o mesmo aconteça com a psicanálise, ambas as ciências da natureza ( $N$ aturwissenschaft), diferentemente do que ocorre com a filosofia e as ciências do espírito (Geistwissenschaft): 
"De maneira repetida, ouvi declarar com desdém que de modo algum se poderia fazer uma ciência com os conceitos supremos tão impreci sos tais como os de libido e de pulsão em psicanálise. Mas há na base dessa reprovação um total desconhecimento do estado das coisas. Os conceitos fundamentais claros e as definições com contornos precisos só são possíveis numa ciência do espírito, na medida em que estas querem incluir no quadro de uma formação de sistema intelectual um domínio de fatos." (FREUD, 1925d, p. 105; SE, XX, p. 58)

Freud não vê outra alternativa senão usar o conceito de pulsão, ainda que este seja obscuro (FREUD, 1915c, p. 163; SE, XIV, p. 117). A pulsão seria, então, uma força psíquica que empurra 0 organismo para descarregar uma pressão dada numa determinada região ou órgão, ela é uma excitação que precisa de descarga. Logo, as excitações corporais dos mais diversos tipos, relativas às zonas erógenas, deveriam também ser pensadas compreendendo montantes de energias que procuram escoamento. Se estivéssemos num quadro em que as pulsões fossem díspares em sua natureza, também poder-se-ia supor diversos tipos de energia, uma para cada tipo de pulsão. Freud não postulou a existência de uma infinidade de energias agindo no nosso interior, tampouco defendeu a presença de apenas uma única energia animando todo o psiquismo. Ele propôs um dualismo pulsional que engloba a diversidade das pulsões parciais, agrupando-as sempre segundo dois tipos básicos diferenciados e em conflito: as de autoconservação e as sexuais, na primeira tópica, e as de vida e morte, na segunda.

Freud sempre manteve em sua teoria o dualismo pulsional, pois isso possibilitava explicar os fenômenos clínicos em função de um conflito dinâmico básico, fornecendo-Ihe um guia metodológico para suas formulações. No entanto, ele precisou modificar o par de pulsões básicas que comporiam esse dualismo. 0 primeiro dualismo pulsional, opondo as pulsões sexuais às de autoconservação, foi apenas parcialmente eficaz na resolução dos problemas próprios à psicanálise, em especial nos que dizem respeito às neuroses ditas de transferência; mas este modelo encontrava dificuldades na explicação de outros fenômenos clínicos, em particular os associados às manifestações psicopatológicas, tais como a hipocondria e as neuroses ditas narcísicas. Tendo em mente essas insuficiências, em 1914, Freud aprimorou sua explicação do funcionamento das pulsões sexuais, propondo que a energia própria à pulsão sexual podia dirigir-se tanto aos objetos externos quanto ao próprio "eu" do paciente. Assim, reconhecendo que o "eu" também poderia ser investido por uma energia sexual e ser tomado como objeto da pulsão sexual, ele passa a agregar às pulsões de autoconservação um complemento libidinal; isso não seria apenas uma característica particular dos processos mórbidos, mas sim caracterizaria, até certo 
ponto, a própria psicologia da pessoa normal. Diz Freud: “ 0 narcisismo, nesse sentido, não seria uma perversão, mas o complemento libidinal do egoísmo inerente à pulsão de autoconservação, da qual, justificadamente, se atribui uma dose a todo ser vivo" (FREUD, 1914c, p. 82; SE, XIV, p. 73). Nesse momento, ele ainda mantém a diferenciação básica entre pulsões de autoconservação e pulsões sexuais, o que deixa em aberto a questão sobre a existência de um ou dois tipos de energia animando essas pulsões.

Se a suposição da existência de forças e energias psíquicas é uma especulação, a diferenciação dos tipos de energia também tem a mesma natureza ficcional. A questão a ser colocada é: Freud tem em mente que tanto a libido como a diferenciação de dois tipos básicos de energias psíquicas são ficções? 0 encadeamento de seu raciocínio no texto "Introdução ao narcisismo" mostra que ele está ciente da natureza especulativa desses conceitos. Após indicar os problemas clínicos que o obrigaram a reformular suas hipóteses sobre as pulsões, introduzindo as noções de "libido do eu" e de "libido do objeto", ele apresenta duas questões a serem explicitadas. Em primeiro lugar, ele pergunta qual rela ção existiria entre um narcisismo e um auto-erotismo (enquanto um estado inicial da libido), pois com essa resposta ele pode reconhecer uma diferença básica entre dois tipos de pulsões.

“É necessário admitir que não existe desde o início, no indivíduo, uma unidade comparável ao eu; o eu tem que ser desenvolvido. Pois bem, as pulsões autoeróticas são iniciais, primordiais; algo, portanto, deve ser agregado ao auto-erotismo, uma nova ação psíquica, para que o narcisismo se constitua." (FREUD, 1914c, p. 84; SE, XIV, p. 77)

Em seguida, indaga sobre o tipo de energia que seria necessário supor, ao seguir o desenvolvimento de suas hipóteses sobre esses problemas clínicos específicos:

"se atribuímos ao eu um investimento primário de libido, por que é necessário distinguir ainda uma libido sexual de uma energia não sexual das pulsões do eu? Supor uma única espécie de energia psíquica não nos pouparia de todas as dificuldades que residem em diferenciar uma energia pulsional do eu da libido do eu, e a libido do eu da libido do objeto?" (Idem)

A solução desse segundo problema leva Freud a um campo desconfortável, visto que estas hipóteses não se apresentam com o peso e a sustentação da observação, ou seja, estamos no campo obscuro das idéias apenas supostas, como se fossem algo real, sabendo de antemão que são apenas idéias: 
"A necessidade de fornecer uma resposta decisiva à segunda pergunta [um ou dois tipos de energia, referidas às pulsões do eu] não pode senão suscitar um mal-estar notável em todo psicanalista. É-se tomado pelo sentimento de ter abandonado a observação em troca de estéreis disputas teóricas; mas não é lícito se abster de uma tentativa de clarificação. Certamente, representações tais com as de libido do eu, energia pulsional do eu e outras semel hantes não são apreensíveis com facilidade, nem seu conteúdo é suficientemente rico." (Idem)

Não será o raciocínio límpido, irrepreensível na sua organização lógica, que decidirá sobre o problema da escolha entre uma ou duas energias fundamentais. É justamente nesse ponto que Freud marca a diferença entre uma especulação, que apresenta teoria e conceitos sem nenhuma ligação direta com os dados empíricos (muitas vezes identificada por Freud às especulações da filosofia), e a especulação científica, que propõe construções auxiliares visando a resolução de certos problemas empíricos (Idem, p. 84-85). Nem a especulação filosófica nem a científica teriam valor objetivo, ou seja, empírico, mas a científica tem um valor heurístico, ela é útil para explicar aquilo que a observação (descrição) dos fatos não pode oferecer.

0 critério que Freud utiliza para julgar qual a melhor hipótese, no que diz respeito à consideração da existência de uma ou mais energias diferenciadas no psiquismo, já que isso não pode ser decidido diretamente pela observação empírica, é heurístico: trata-se de saber qual das hipóteses é mais frutífera para explicar os fenômenos aos quais ela se aplica. A hipótese escolhida tem, portanto, a marca da provisoriedade: ela é a melhor (mais eficiente) até o momento, até que algo melhor se apresente. Freud especifica o valor heurístico de suas hipóteses sobre uma "libido do eu" e uma "libido do objeto":

"O valor dos conceitos de libido do eu e libido de objeto reside no fato de que provêm do processamento das características íntimas dos processos neuróticos e psicóticos. A separação da libido em uma que é própria ao eu e uma dirigida aos objetos é a inevitável prolongação de um primeiro pressuposto que dividiu [entre si as] pulsões sexuais e pulsões do eu. Esta separação foi-me imposta, ao menos, pela análise das neuroses de transferência puras (histeria e neurose obsessiva), e tudo o que sei é que todas as tentativas para dar conta desses fenômenos por outros meios fracassaram radical mente." (Idem, p. 85)

Mas Freud acredita na libido como energia psíquica? Sim e não. Se entendemos "acreditar" como sinônimo de crer na realidade empírica ou no referente empírico para o conceito de libido, então podemos dizer que Freud não acredita; mas se entendemos "acreditar" como sinônimo de crer que tudo se passa 
como se uma energia psíquica existisse, então somos levados a dizer que Freud crê nessa ou nessas energias.

Um fato curioso corrobora minha interpretação da perspectiva em que Freud se colocava, epistemológica e metodologicamente falando. Em 1910, Willem Ostwald (1853-1932) - prêmio Nobel de química em 1909, representante do ponto de vista energetista, que considera a energia o fundamento de todos os movimentos no universo - convidara Freud a colaborar com um artigo: “Um signo dos tempos: eu recebi uma carta dizendo que o Geheimratt ${ }^{4}$ Ostwald gostaria muito de um ensaio meu nos Annalen der Naturphilosophie. Se eu fosse mais ambicioso, teria já aceito e saberia o que escrever. Mas eu ainda estou longe de decidir" (FREUD \& JUNG, 1992, carta a Jung de 02/ 05/ 1910, p. 409). Algumas semanas mais tarde ele se mostrou indeciso e cauteloso quanto à sua participação: "Como signo dos tempos eu mencionei ainda que o Sr. Gehemrat Ostwald e a N ew Presse deViena me pediram ambos um artigo. Eu fiz promessas a um, disse não a outro, dado que em Viena eu devo ser particularmente reservado" (FREUD \& JUNG, 1992, carta a Jung de 26/05/ 1910, p. 416). Jones comenta que Freud havia aceitado o convite de Ostwald em 16 de maio de 1910, mas que jamais enviou o artigo para publicação (cf. JONES, 2000, p. 82). Nessa mesma época, em 1911, Freud assinou um manifesto público, junto com Mach, para a fundação de uma "Sociedade para a Filosofia Positivista".${ }^{5}$ A recusa de Freud em contribuir com Ostwald não parece se justificar simplesmente porque ele queria manter-se independente em suas posições, mas pode ser também entendida em função da sua não-aderência às teses de 0 stwald, especialmente no que diz respeito à redução do fundamento causal creditado às energias - fossem elas consideradas como tendo um valor empírico, ou como tendo um valor apenas heurístico.

No desenvolvimento de suas teorias sobre o funcionamento psíquico, Freud reiterou o ponto de vista dinâmico, com seu dualismo básico de forças em conflito, como princípio básico de intelecção, enriqueceu-o com o ponto de vista econômico, com a suposição de quantidades de energia que se deslocam, e com o tópico, com a ficção teórica (FREU D, 1900a, p. 513) de sistemas psíquicos diferenciados espacialmente figuráveis. $\mathrm{E}$ a esse conjunto de explicações teóricas ele nomeou metapsicologia: "Eu proponho que se fale de uma apresentação metapsicológica quando nós conseguimos descrever um processo psíquico segundo suas relações dinâmicas, tópicas e econômicas" (FREUD, 1915e, p. 221; SE, XIV, p. 182). A metapsicologia pode ser considerada, portanto, como sendo um conjunto de ficções teóricas ou, como diz Freud, como uma supraestrutura

\footnotetext{
${ }^{4} \mathrm{Gehemart}$ tem aqui o sentido de identificar Ostwald como uma autoridade reconhecida publicamente, como um ti po de conselheiro oficial para questões relativas à ciência.

${ }^{5}$ Cf. a apresentação e comentário desse documento em FULGENCIO, 2001b.
} 
especulativa (Spekulativer Ü berbau) da psicanálise (FREUD, 1925d, p. 80; SE, XX, p. 32), sempre aberta a transformações, substituições e abandonos.

0 uso de conceitos especulativos de validade apenas heurística fica particularmente evidente no momento em que Freud se refere à diferenciação entre libido do eu e do objeto, comentando que esses conceitos não são o fundamento da psicanálise e podem ser, sem prejuízo, substituídos:

"É que estas idéias [as de libido do eu e de objeto] não são o fundamento da ciência, sobre os quais tudo repousa: este fundamento, ao contrário, é somente a observação. Não constituindo as fundações mas o cume de todo edifício, elas podem, sem prejuízo, ser substituídas e retiradas." (FREUD, 1914c, p. 85; SE, XIV, p. 76)

As ficções heurísticas, tais como as formuladas pelos conceitos de libido, pulsão, aparelho psíquico etc., tornam possível não só organizar o próprio material das observações como propor explicações para os fenômenos psíquicos, ainda que elas mesmas jamais possam ser observadas. Dado seu caráter heurístico, em certo sentido elas estão sempre sujeitas a serem abandonadas por algo mais eficaz.

A teoria da libido será articulada com todo o processo de desenvolvimento do psiquismo, visto que este será pensado pela maneira como são estabelecidas as relações entre os desejos e seus "objetos", noutras palavras, pelos tipos de investimentos libidinais que o indivíduo realiza consigo mesmo e com o mundo (seus objetos), ainda que, em certos casos, esse mundo seja o próprio indivíduo. A teoria do desenvolvimento da libido corresponde à parte especulativa da teoria do desenvolvimento da sexualidade que, subdividida em fases (oral, anal, fálica, genital), explica uma série de comportamentos observáveis, associando-os à teoria da energia sexual (libido) que investe tais e tais objetos, de tal e tal modo, segundo as fases do desenvolvimento.

0 fato de Freud ter substituído o primeiro dualismo pulsional pelo segundo não modifica em nada a natureza especulativa de suas hipóteses de fundo. Se a passagem da primeira para a segunda tópica possibilita considerar que tanto as pulsões sexuais como as de autoconservação seriam impulsionadas pelo mesmo tipo de energia (a libido), ora investida nos objetos considerados externos ao eu, ora no próprio eu, a questão da existência de um ou dois tipos de energias psíquicas fundamentais fica transferida, sem solução, para o novo dualismo pulsional: a libido, como energia sexual, ficaria referida à pulsão de vida, mas que energia impulsionaria a pulsão de morte?

Talvez fosse de se esperar que Freud propusesse e nomeasse energias específicas movendo cada uma de suas pulsões expressas nos conflitos pulsionais 
básicos - seja no primeiro dualismo seja no segundo. No entanto, só a energia sexual é nomeada. Ou ainda, por outro lado, que ele defendesse uma energia única impulsionando pulsões díspares. A opção de Freud foi nomear a energia sexual, dando ênfase à importância da sexualidade na etiologia das neuroses e na constituição do psiquismo, sem se ocupar diretamente com o problema de considerar um, dois ou mais tipos de energia.

0 critério que leva Freud a não se ocupar com esse problema também pode ser creditado ao valor heurístico que ele reconhece no tema. Não se trata, para ele, de construir um edifício logicamente irrepreensível, em que todos os conceitos se articulem harmonicamente e sem lacunas, mas sim de propor conceitos e teorias que possam ter utilidade para o método psicanalítico - método que procura a cura de certos tipos de sofrimentos psíquicos (Cf. FREUD, 1913j, p. 187; SE, XIII, p. 165; FREUD, 1923a, p. 183; SE, XVIII, p. 235). Assim, parece que Freud não via necessidade nem utilidade no desenvolvimento desse tema ( uma ou mais energias díspares), tomando-0, talvez, apenas como uma questão lógica (mas vazia), sem nenhum interesse prático evidente.

Essas análises nos levam a considerar em que nível determinados conceitos são colocados, estabelecendo a diferença entre conceitos empíricos e conceitos especulativos, marcando claramente o lugar em que Freud introduz suas especulações, sem que isso implique considerar que a psicanálise tenha abandonado o campo da ciência experimental, que obriga a ter nos dados observáveis e nos problemas a resolver 0 critério de aplicabilidade e correção (heurística) de suas teorias.

Recebido em 7/3/2002. Aprovado em 6/ 5/ 2002.

\section{BIBLIOGRAFIA}

FREUD, S. Oeuvres complètes Psychanalyse. Diretores da publicação: André Bourguignon e Pierre Cotet; diretor científico: Jean Laplanche, Paris, PUF.

(1912c/ 1998) “Des types d'entrée dans la maladie névrotique”, v. XI, p. $117-1.126$.

(1913m/ 1998) "Sur la psychanalyse”, v. XI, p. 27-40.

(1915c/ 1988) "Pulsions et destin des pulsions", v. XIII, p. 161-186.

(1915e/ 1988) "L'inconscient", v. XIII, p. 203-242.

(1916-17/ 2000) "Leçons d'introduction a la psychanalyse", v. XIV, p. $1-480$.

(1923a/ 1991) "Psychanalyse" et "Théorie de la libido", v. XVI, p. 181-208. 
(1925d/ 1992) "Autoprésentation", v. XVII, p. 51-122.

(1933a/ 1995) "Nouvelles suite des leçons d'introdution à la psychanalyse", v. XIX, p. 83-268.

(1980) L'intrepretation des rêves, 1900a, Paris, PUF.

. (1913j/ 1995) "L'intérêt de la psychanalyse", in Résultats, idées, problèmes I, 1890-1920. Paris, PUF, p. 187-214.

(1914c/1969) "Pour introduire le narcissisme", La vie sexuelle.

Paris, PUF, p. 81-107.

. (1940a/ 1985) Abrégé de psychanalyse, Paris, PUF.

. \& JUNG, C. G. (1992) Correspondance 1906-1914. Paris, Gallimard.

FULGENCIO, L. (2001a) "O método especulativo em Freud", tese de doutorado, PUC-SP.

(2001b) "Apresentação e comentários do documento: Convocação para a fundação de uma 'Sociedade para a Filosofia Positivista'", in Natureza Humana, 2/ 2, São Paulo, Educ, Jul-dez, p. 429-438.

JONES, E. (2000) La vie et l'oeuvre de Sigmund Freud, v. II (1955), Paris, PUF. LOPARIC, Z. (1999) "O conceito deTrieb na filosofia e na psicanálise", in Filosofia e psicanálise: um diálogo, MACHADO, J. A. T. (org.) , Porto Alegre, Edipc-RS.

MACH, E. (1905/ 1922) La conaissance et l'erreur, Paris, Flammarion.

. (1883/ 1987) La mécanique. Exposé Historique et critique de son développement, Paris, Éditions Acques Gabay.

RAPAPORT, D. (1960/ 1982) A estrutura da teoria psicanalítica, São Paulo, Perspectiva.

Leopoldo Fulgencio

ful@that.com.br 